\title{
ANALISIS PERSEDIAAN BAHAN BAKU PADA AGROINDUSTRI KRIPIK BUAH SANUR DI KABUPATEN MALANG
}

\author{
Nineng Puspito Ratih ${ }^{1}$, Anik Suwandari $^{2} \&$ M. Rondhi ${ }^{2}$ \\ ${ }^{1}$ Mahasiswa, Program Studi Agribisnis Fakultas Pertanian Universitas Jember \\ ${ }_{2}^{2}$ Staf Pengajar, Program Studi Agribisnis Fakultas Pertanian Universitas Jember \\ email:nineratih@gmail.com
}

\begin{abstract}
Various fruits can be tranformed into delicious edible foods like chips. That was a basic idea which inspired "Sanur" Fruit Chips Agroinduntry to make chips which based on fruits processing. This agroindustry still performs traditional methods to manage its fruit inventory as raw material. This lead to a fluctuation and uncertainty in inventory stock. The traditional inventory in this agroindustry also caused a bottleneck in production process. The research was aimed to : (1) determine the economic order quantity of fruit chips agroindustry. (2) determine the most efficient re-order point of inventory in "Sanur" Fruit Chips Agroindustry. The research was descriptive and analytical. The key informant was selected purposively based on some criteria. Data was collected by using interview and observation. The result showed that : (1) economic order quantity was more preferable than Lot for Lot and tradional methods. (2) the traditional re-order point method in "Sanur" fruit chips agroindustry was not efficient. It was indicated by the safety stock, the amount of procurement and the inventory of minimum raw materials which showed full uncertain.
\end{abstract}

Keywords: Economic Order Quantity, Lot For Lot, Re-Order Point.

\section{PENDAHULUAN}

Orientasi pembangunan pertanian dalam era globalisasi saat ini perlu dipikir ulang. Di masa lalu pembangunan pertanian diarahkan untuk menghasilkan produksi primer, akan tetapi untuk saat ini dan masa mendatang orientasi pembangunan pertanian harus diarahkan pada agroindustri. Pembangunan agroindustri disepakati sebagai lanjutan dari pembangunan pertanian. Hal ini telah dibuktikan bahwa agroindustri mampu meningkatkan pendapatan para pelaku agribisnis.

Agroindustri Kripik Buah Sanur mengolah beragam jenis buah menjadi kripik. Buah yang diolah diantaranya salak, nangka, pisang dan nanas. Bahan baku yang digunakan bersifat fluktuatif. Sehingga, agroindustri menerima semua pengiriman bahan baku dari semua pemasok, tujuannya supaya tidak terjadi kekurangan bahan baku pada saat proses produksi berlangsung.

Metode persediaan bahan baku yang diterapkan Agroindustri Kripik Buah
Sanur menimbulkan frekuensi pesan dan jumlah persediaan bahan baku tidak menentu. Jumlah frekuensi pesan yang tidak menentu ini mengakibatkan pengeluaran biaya pemesanan tidak terkontrol. Jumlah persediaan bahan baku di gudang terkadang sedikit dan terkadang melimpah. Keadaan ini apabila dibiarkan secara terus menerus mengakibatkan jumlah produksi tidak menentu serta sewaktu-waktu dapat menimbulkan kemacetan produksi di Agroindustri Kripik Buah Sanur.

Jangka waktu proses produksi masing-masing komoditas berbeda, tergantung ketersediaan bahan baku di pasaran dan pemesanan yang dilakukan agroindustri. Komoditas salak diproduksi pada bulan januari hingga bulan mei dan awal bulan agustus. Komoditas nangka diproduksi pada bulan oktober hingga bulan desember. Komoditas pisang diproduksi pada bulan juni dan bulan juli sedangkan komoditas nanas diproduksi pada pertengahan bulan agustus. Pada bulan september terjadi kekosongan produksi, dikarenakan bahan 
baku sulit diperoleh. Selama proses produksi pada tahun 2015, agroindustri melakukan pemesanan ulang bahan baku apabila persediaan di gudang dirasa sudah tidak mencukupi.

Berdasarkan fenomena-fenomena yang ada, peneliti merumuskan permasalahan-permasalahan menarik untuk diteliti, diantaranya ; apakah tingkat pemesanan bahan baku pada agroindustri sudah ekonomis dan bagaimana tingkat pemesanan ulang bahan baku yang efisien untuk agroindustri. Berdasarkan permasalahan yang diteliti, maka tujuan dari penelitian ini adalah ; (1) mengetahui tingkat persediaan bahan baku yang ekonomis (2) mengetahui tingkat pemesanan ulang bahan baku yang efisien pada Agroindustri Kripik Buah Sanur.

Beberapa penelitian dipakai untuk membantu memecahkan permasalahan yang diangkat peneliti. Permasalahan mengenai persediaan bahan baku, peneliti mengacu pada penelitian Muzayyanah dkk (2015), mengenai pengendalian biji kakao pada pabrik Delicacao Bali. Penelitian ini menerangkan bahwa ada perbedaan total biaya persediaan. Perbandingan total biaya persediaan metode tradisional, metode LFL dan metode EOQ berturut-turut adalah Rp. 19 juta, Rp. 8,6 juta, Rp 4 juta.

Masalah kedua mengenai pemesanan ulang bahan baku, peneliti mengacu pada penelitian Artawan (2015), yang menjelaskan bahwa pembelian persediaan Perusahaan Rumah Makan Janggar Ulam mengalami penurunan biaya apabila perusahaan menggunakan metode ROP. ROP juga mampu menentukan kapan waktu yang baik untuk melakukan pemesanan ulang bahan baku dengan diketahuinya safety stock. Menurut penelitian-penelitian terdahulu yang diacu, diketahui bahwa metode yang digunakan perusahaan belum ekonomis dan belum efisien.

\section{METODE PENELITIAN}

Penelitian ini dilaksanakan di Agroindustri Kripik Buah Sanur di Desa Tirtoyudo, Kecamatan Tirtoyudo, Kabupaten Malang. Penentuan lokasi penelitian dilakukan secara sengaja menggunakan metode purposive dengan pertimbangan : (1) di wilayah tersebut terdapat sentra produksi kripik buah yang melimpah, (2) Mayoritas agroindustri yang ada mengolah kripik yang sejenis, yakni salak, nangka, pisang dan nanas.
Metode penelitian yang dilakukan dalam penelitian ini adalah metode deskriptif analitik dan komparatif. Metode pengambilan data dilakukan dengan wawancara dan observasi langsung dengan lebih dulu menentukan informan kunci. Informaan kunci pada penelitian ini adalah manajer dan kepala bidang produksi. Data yang diperoleh peneliti adalah data primer dan data sekunder.

Menurut Haming dan Nurnajamuddin (2012), Material Requierement Planning adalah suatu metode yang dimulai dengan kegiatan peramalan terhadap permintaan produk jadi yang independen. Teknik penentuan besarnya pemesanan bahan baku yang dipilih yakni teknik EOQ dan LFL. Teknik LFL melakukan pemesanan bahan baku sesuai dengan jumlah kebutuhan bersih dalam periode yang bersangkutan. Sedangkan teknik EOQ memesan bahan baku sesuai dengan rumus matematika sebagai berikut :

$Q^{*}=\frac{\sqrt{2 D S}}{H}$

\section{Keterangan :}

$\mathrm{D}=$ Jumlah kebutuhan barang (unit/tahun). $\mathrm{S}=$ Biaya Pemesanan (Rp/pemesanan).

$\mathrm{H}=$ biaya penyimpanan ( $\mathrm{Rp} / \mathrm{unit} / \mathrm{tahun})$.

$\mathrm{Q}=$ jumlah pemesanan (unit/pesanan).

Hasil dari penelitian ini yakni dengan membandingkan metode persediaan bahan baku yang diterapkan agroindustri, metode MRP teknik LFL dan EOQ. Metode yang memiliki tingkat persediaan paling ekonomis dapat direkomendasikan untuk diterapkan Agroindustri Kripik Buah Sanur.

Menurut Herdjanto (2007), Re-Order Point (ROP) merupakan jumlah persediaan bahan baku yang menandai harus diadakan pemesanan ulang sehingga kedatangan atau penerimaan barang yang dipesan tepat waktu. Pada penelitian ini, metode pemesanan ulang bahan baku yang diterapkan Agroindustri Kripik Buah Sanur dibandingkan dengan metode Re-order Point. Metode yang memiliki pemesanan ulang bahan baku yang efisien yang akan direkomendasikan untuk Agroindustri Kripik Buah Sanur. 


\section{HASIL DAN PEMBAHASAN Persediaan Bahan Baku Agroindustri Kripik Buah Sanur}

Tersedianya bahan baku yang cukup dan kontinu bagi suatu agroindustri sangatlah penting, karena jumah ketersediaan bahan baku dapat mempengaruhi laju produksi. Maka dari itu diperlukan manajemen stok bahan baku yang baik dalam suatu agroindustri. Manajemen stok berarti membeli kemudian menyimpannya di gudang untuk sementara waktu hingga digunakan (Soekartawi, 2005).

Agroindustri Kripik Buah Sanur merupakan agroindustri yang mengolah buah-buahan menjadi kripik. Pada tahun 2015 agroindustri ini mengolah empat macam buah, diantaranya buah salak, buah nangka, buah pisang dan buah nanas. Pada proses persediaannya agroindustri mengeluarkan tiga macam biaya, diantaranya biaya pemesanan, penyimpanan dan pembelian bahan baku. Umumnya biaya persediaan bahan baku yang dikeluarkan beragam yang terangkum dalam tiga pengeluaran biaya, diantaranya biaya pemesanan, biaya penyimpanan, dan biaya kekurangan persediaan.

Biaya pemesanan adalah biaya yang dikeluarkan dalam proses pemesanan bahan baku. Besarnya biaya pemesanan bahan baku masing-masing komoditas sama, yakni sebesar Rp. 10.000 per pemesanan. Biaya pembelian adalah besarnya kuantitas bahan baku yang dipesan. Besarnya biaya pembelian bahan baku sesuai dengan jumlah bahan baku yang dipesan dikalikan dengan harga masing-masing komoditas. Biaya penyimpanan merupakan biaya penyusutan buah akibat buah tidak layak produksi atau busuk. Berikut adalah biaya penyimpanan bahan baku pada Agroindustri Kripik Buah Sanur.

Tabel 1. Biaya penyimpanan bahan baku

\begin{tabular}{lrrr}
\hline $\begin{array}{c}\text { Bahan } \\
\text { Baku }\end{array}$ & $\begin{array}{c}\text { Penyusu- } \\
\text { tan } / \mathbf{k g}\end{array}$ & $\begin{array}{c}\text { Harga } \\
\text { BB/ kg }\end{array}$ & $\begin{array}{c}\text { Biaya Sim- } \\
\text { pan(Rp) }\end{array}$ \\
\hline Salak & $10 \%$ & 3.000 & 300 \\
Nangka & $7 \%$ & 2.800 & 196 \\
Pisang & $10 \%$ & 2.000 & 200 \\
Nanas & $2 \%$ & 3.500 & 70 \\
\hline \multicolumn{4}{l}{ Sumber : Data Primer Diolah (2016) }
\end{tabular}

Berdasarkan Tabel 1. diketahui besarnya biaya penyimpanan bahan baku tergantung besarnya penyusutan buah dan harga bahan baku per kg. Biaya penyimpanan salak, nangka, pisang dan nanas berturut-turut adalah Rp300;
Rp196; Rp200 dan Rp70.

1. Persediaan Bahan Baku Agroindustri

Agroindustri tidak memiliki metode persediaan bahan baku yang pasti. Metode persediaan bahan baku yang diterapkan Agroindustri Kripik Buah Sanur berdasarkan pengalaman agroindustri. Tersedianya bahan baku yang cukup dan kontinu bagi suatu agroindustri sangatlah penting, karena jumah ketersediaan bahan baku dapat mempengaruhi laju produksi. Maka dari itu diperlukan manajemen stok bahan baku yang baik dalam suatu agroindustri (Soekartawi, 2005). Menurut perhitungan persediaan bahan baku Agroindustri Kripik Buah Sanur, diketahui frekuensi pemesanan bahan baku salak, nangka, pisang dan nanas berturut-turut adalah 47 kali, 21 kali, 23 kali, 5 kali selama tahun 2015. Lebih jelasnya, tabel berikut ini menjelaskan mengenai rangkuman persediaan bahan baku yang diterapkan Agroindustri Kripik Buah Sanur.

2. Persediaan bahan baku menggunakan teknik Lot For Lot

Hasil perhitungan teknik LFL dalam periode satu hari, diketahui rata-rata persediaan bahan baku yang mengalami proses penyimpanan untuk salak, nangka, pisang dan nanas berturut-turut adalah

Berdasarkan tabel 4, diketahui jumlah frekuensi pesan teknik LFL lebih rendah daripada frekuensi pesan yang diterapkan agroindustri. Pada perhitungan teknik LFL diatas, didapat pengeluaran biaya persediaan sebagai berikut.

Berdasarkan tabel 5 diketahui total pengelaran biaya persediaan tertinggi berturut-turut adalah salak, nangka, pisang dan nanas. 
Tabel 2. Metode Persediaan Bahan Baku Agroindustri Kripik Buah Sanur

\begin{tabular}{|c|c|c|c|c|c|c|c|c|}
\hline \multirow[t]{2}{*}{ Minggu } & \multicolumn{2}{|c|}{ Januari-Mei dan Agustus } & \multicolumn{2}{|c|}{ Juni-Juli } & \multicolumn{2}{|c|}{ Agustus } & \multicolumn{2}{|c|}{ Oktober-Desember } \\
\hline & $\begin{array}{l}\text { Persediaan } \\
\text { BB. (kg) }\end{array}$ & $\begin{array}{l}\text { Pembelian } \\
\text { BB. (kg) }\end{array}$ & $\begin{array}{l}\text { Persediaan } \\
\text { BB. }(\mathrm{kg})\end{array}$ & $\begin{array}{l}\text { Pembelian } \\
\text { BB. (kg) }\end{array}$ & $\begin{array}{l}\text { Persediaan } \\
\text { BB. }(\mathrm{kg})\end{array}$ & $\begin{array}{l}\text { P e m b e - } \\
\text { liaan BB. } \\
(\mathrm{kg})\end{array}$ & $\begin{array}{l}\text { P e r s e - } \\
\text { diaan BB. } \\
(\mathrm{kg})\end{array}$ & $\begin{array}{l}\text { Pembeliaan } \\
\text { BB. }(\mathrm{kg})\end{array}$ \\
\hline 1 & 25 & 500 & 7,9 & 165,2 & 0,5 & 201 & 30,5 & 880 \\
\hline 2 & 82,75 & 655 & 26,8 & 221 & 0,5 & 221 & 103 & 987 \\
\hline 3 & 146,05 & 611 & 47,3 & 199 & - & - & 196,5 & 987 \\
\hline 4 & 209,35 & 655 & 65,8 & 181 & - & - & 289,5 & 789 \\
\hline 5 & 270,05 & 559 & 74,15 & 193,3 & - & - & 365,5 & 993 \\
\hline 6 & 325,15 & 543 & 69,5 & 175 & - & - & 431 & 899 \\
\hline 7 & 386,8 & 690 & 54,5 & 189 & - & - & 462 & 1009 \\
\hline 8 & 449,15 & 557 & 24,75 & 166 & - & - & 458,5 & 987 \\
\hline 9 & 496,5 & 390 & 3 & 100 & - & - & 310 & 899 \\
\hline 10 & 537,6 & 432 & - & - & - & - & 168 & 996 \\
\hline 11 & 579,3 & 408 & - & - & - & - & 206,5 & 1039 \\
\hline 12 & 626,9 & 550 & - & - & - & - & 127,5 & 890 \\
\hline 13 & 676 & 432 & - & - & - & - & 6,5 & 1005 \\
\hline 14 & 717,6 & 400 & - & - & - & - & - & - \\
\hline 15 & 763,5 & 518 & - & - & - & - & - & - \\
\hline 16 & 816,6 & 544 & - & - & - & - & - & - \\
\hline 17 & 787,3 & 322 & - & - & - & - & - & - \\
\hline 18 & 683,8 & 657 & - & - & - & - & - & - \\
\hline 19 & 610,3 & 662 & - & - & - & - & - & - \\
\hline 20 & 527,8 & 431 & - & - & - & - & - & - \\
\hline 21 & 396,3 & 456 & - & - & - & - & - & - \\
\hline 22 & 281,6 & 455 & - & - & - & - & - & \\
\hline 23 & 121,2 & 343 & - & - & - & - & - & - \\
\hline Total & $10.516,6$ & 11770 & 373,7 & 1589,5 & 1 & 422 & 3.155 & 12360 \\
\hline Rata-rata & 457,2 & 511,7 & 41,5 & 176,6 & 0,5 & 211 & 242,7 & 950.7 \\
\hline
\end{tabular}

Sumber : Data Primer Diolah (2016).

Berdasarkan tabel 2, diketahui komoditas salak mengalami proses produksi terpanjang, sedangkan produksi terpendek adalah nanas hanya pada awal bulan agustus. Menurut tabel diatas diketahui jumlah pembelian salak, nangka, pisang dan nanas berturut-turut adalah $11.770 \mathrm{~kg}$ ; $12.360 \mathrm{~kg} ; 1.589,5 \mathrm{~kg}$ dan $422 \mathrm{~kg}$. Menurut tabel diatas, diketahui biaya persediaan yang dikeluarkan, yakni sebagai berikut.
Berdasarkan tabel 3, diketahui biaya pengeluaran tertinggi adalah salak dan total biaya persediaan terendah nanas.

Tabel 3. Biaya Persediaan Agroindustri Kripik Buah Sanur

\begin{tabular}{lrrrr}
\hline Bahan Baku & Biaya Pesan (Rp) & $\begin{array}{c}\text { Biaya Simpan } \\
\text { (Rp) }\end{array}$ & $\begin{array}{c}\text { Biaya Pembelian } \\
\text { Bahan Baku } \\
\text { (Rp) }\end{array}$ & $\begin{array}{c}\text { Total Biaya Per- } \\
\text { sediaan (Rp) }\end{array}$ \\
\hline Salak & 470.000 & 137.100 & 35.310 .000 & 35.917 .100 \\
Nangka & 210.000 & 47.569 & 34.608 .000 & 34.865 .569 \\
Pisang & 230.000 & 8.304 & 3.179 .000 & 3.417 .304 \\
Nanas & 50.000 & 35 & 1.477 .000 & 1.527 .350 \\
\hline Sumber:
\end{tabular}

Sumber : Data Primer Diolah (2016). 
Tabel 4. Persediaan Bahan Baku Menggunakan Teknik Lot For Lot

\begin{tabular}{|c|c|c|c|c|c|c|c|c|}
\hline \multirow[t]{2}{*}{ Bulan } & \multicolumn{2}{|c|}{ Salak } & \multicolumn{2}{|c|}{ Nangka } & \multicolumn{2}{|c|}{ Pisang } & \multicolumn{2}{|c|}{ Nanas } \\
\hline & $\begin{array}{l}\text { Frek. } \\
\text { (kali) }\end{array}$ & $\begin{array}{c}\text { Kuant. } \\
\text { (kg) }\end{array}$ & $\begin{array}{l}\text { Frek. } \\
\text { (kali) }\end{array}$ & $\begin{array}{c}\text { Kuant. } \\
\text { (kg) }\end{array}$ & $\begin{array}{l}\text { Frek. } \\
\text { (kali) }\end{array}$ & $\begin{array}{c}\text { Kuant. } \\
\text { (kg) }\end{array}$ & $\begin{array}{l}\text { Frek. } \\
\text { (kali) }\end{array}$ & $\begin{array}{c}\text { Kuant } \\
\text { (kg) }\end{array}$ \\
\hline Januari & 5 & 2.421 & - & - & - & - & - & - \\
\hline Februari & 4 & 2.349 & - & - & - & - & - & - \\
\hline Maret & 4 & 1.780 & - & - & - & - & - & - \\
\hline April & 4 & 1.894 & - & - & - & - & - & - \\
\hline Mei & 5 & 2.528 & - & - & - & - & - & - \\
\hline Juni & - & - & - & - & 5 & 766,2 & - & - \\
\hline Juli & - & - & - & - & 4 & 723,3 & - & - \\
\hline Agustus & 1 & 798 & - & - & - & - & 2 & 422 \\
\hline September & - & - & - & - & - & - & - & \\
\hline Oktober & - & - & 5 & 3.643 & - & - & - & - \\
\hline Nopember & - & - & 4 & 3.888 & - & - & - & - \\
\hline Desember & - & - & 4 & 4.829 & - & - & - & - \\
\hline Total & 23 & 11.770 & 13 & 12.360 & 9 & 1589,5 & 2 & 422 \\
\hline
\end{tabular}

Berdasarkan tabel 4, diketahui jumlah frekuensi pesan teknik LFL lebih rendah daripada frekuensi pesan yang diterapkan agroindustri. Pada perhitungan teknik LFL diatas, didapat pengeluaran biaya persediaan sebagai berikut.

Berdasarkan tabel 5 diketahui total pengelaran biaya persediaan tertinggi berturut-turut adalah salak, nangka, pisang dan nanas.

3.Persediaan Bahan Baku Menggunakan Teknik EOQ

Nilai EOQ untuk salak, nangka, pisang dan nanas berturut-turut adalah $885,8 \mathrm{~kg} ; 1123$ $\mathrm{kg}$; 393,4 kg dan $347 \mathrm{~kg}$. Nilai EOQ digunakan sebagai patokan jumlah pemesanan bahan baku menggunakan metode MRP. Dari perhitungan metode MRP teknik EOQ diketahui rata-rata persediaan bahan baku yang mengalami proses penyimpanan digudang untuk salak, nangka, pisang dan nanas berturut-turut sebe- sar $611,261 \mathrm{~kg} ; 592,0769 \mathrm{~kg} ; 260,5 \mathrm{~kg}$ dan 73 $\mathrm{kg}$. Lebih jelasnya, berikut perhitungan persediaan bahan baku menggunakan EOQ.

Berdasarkan perhitungan teknik Economic Order Quantity pada tabel 6, diketahui jumlah frekuensi pesan untuk salak sebanyak 14 kali, nangka sebanyak 11 kali, pisang sebanyak 4 kali dan nanas sebanyak 2 kali. Dari tabel diatas, diketahui pengeluaran biaya persediaan teknik EOQ pada tabel 7.

Berdasarkan tabel 7, diketahui besarnya total biaya persediaan dari yang tertinggi bila menggunakan teknik EOQ adalah salak, nang$\mathrm{ka}$, pisang dan nanas. Besarnya perbandingan biaya yang dikeluarkan pada penggunaan ketiga metode perhitungan persediaan bahan baku Agroindustri Kripik Buah Sanur pada tahun 2015 dapat diamati pada tabel 8 .

Tabel 5. Biaya Persediaan Bahan Baku Menggunakan Teknik Lot For Lot

\begin{tabular}{lrrrr}
\hline Bahan Baku & $\begin{array}{c}\text { Biaya Pesan } \\
\text { (Rp) }\end{array}$ & $\begin{array}{c}\text { Biaya Simpan } \\
(\text { Rp) }\end{array}$ & $\begin{array}{c}\text { Biaya Pembelian } \\
\text { Bahan Baku } \\
\text { (Rp) }\end{array}$ & $\begin{array}{c}\text { Total Biaya Per- } \\
\text { sediaan (Rp) }\end{array}$ \\
\hline Salak & 230.000 & 485.400 & 35.310 .000 & 36.025 .400 \\
Nangka & 130.000 & 539.451 & 34.608 .000 & 35.277 .451 \\
Pisang & 90.000 & 104.000 & 3.179 .000 & 3.373 .000 \\
Nanas & 20.000 & 50.715 & 1.477 .000 & 1.547 .715 \\
\hline
\end{tabular}

Sumber : Data Primer Diolah (2016). 
Tabel 6. Persediaan Bahan Baku Menggunakan Teknik Economic Order Quantity

\begin{tabular}{|c|c|c|c|c|c|c|c|c|}
\hline \multirow[t]{2}{*}{ Bulan } & \multicolumn{2}{|c|}{ Salak } & \multicolumn{2}{|c|}{ Nangka } & \multicolumn{2}{|c|}{ Pisang } & \multicolumn{2}{|c|}{ Nanas } \\
\hline & $\begin{array}{l}\text { Frek. } \\
\text { (kali) }\end{array}$ & $\begin{array}{c}\text { Kuant. } \\
\text { (kg) }\end{array}$ & $\begin{array}{l}\text { Frek. } \\
\text { (kali) }\end{array}$ & $\begin{array}{c}\text { Kuant. } \\
\text { (kg) }\end{array}$ & $\begin{array}{l}\text { Frek. } \\
\text { (kali) }\end{array}$ & $\begin{array}{c}\text { Kuant. } \\
\text { (kg) }\end{array}$ & $\begin{array}{l}\text { Frek. } \\
\text { (kal) }\end{array}$ & $\begin{array}{c}\text { Kuant. } \\
\text { (kg) }\end{array}$ \\
\hline Januari & 4 & $2.657,4$ & - & - & - & - & - & - \\
\hline Februari & 3 & $2.657,4$ & - & - & - & - & - & - \\
\hline Maret & 2 & $1.771,6$ & - & - & - & - & - & - \\
\hline April & 2 & $1.771,6$ & - & - & - & - & - & - \\
\hline Mei & 2 & $2.657,4$ & - & - & - & - & - & - \\
\hline Juni & - & - & - & - & 3 & $1.196,1$ & - & - \\
\hline Juli & - & - & - & - & 1 & 393,4 & - & - \\
\hline Agustus & 1 & 254,6 & - & - & - & - & 2 & 422 \\
\hline September & - & - & - & - & - & - & - & \\
\hline Oktober & - & - & 5 & 4.499 & - & - & - & - \\
\hline Nopember & - & - & 3 & 3.369 & - & - & - & - \\
\hline Desember & - & - & 3 & 4.499 & - & - & - & - \\
\hline Total & 14 & 11.770 & 11 & 12.360 & 4 & $1.589,5$ & 2 & 422 \\
\hline $\begin{array}{l}\text { Sumber : Data Pr } \\
\text { Berdase } \\
\text { wa pengeluar } \\
\text { sama untuk } \\
\text { nakan jumlah } \\
\text { jumlahnya. S} \\
\text { san dan biaya } \\
\text { yang dikeluar } \\
\text { han baku yan } \\
\text { biaya pesan, } \\
\text { kan pemesana } \\
\text { lah pemesana } \\
\text { ini mengakiba } \\
\text { sediaan di gu } \\
\text { simpan. Berb } \\
\text { metode LFL } \\
\text { minggu, deng } \\
\text { san sesuai ket } \\
\text { yang dilakuk } \\
\text { biaya simpan } \\
\text { beda dengan } \\
\text { uarkan hampi } \\
\text { biaya simpan. }\end{array}$ & $\begin{array}{l}\text { mer Diolah } \\
\text { rkan tab } \\
n \text { biaya } p \\
\text { nasing-ma } \\
\text { bahan bal } \\
\text { dangkan } \\
\text { simpan be } \\
\text { can oleh } 1 \\
\text { diterapk } \\
\text { karenakar } \\
\text { a sesering } \\
\text { yang tic } \\
\text { tkan tidak } \\
\text { lang sehir } \\
\text { eda deng. } \\
\text { Pemesar } \\
\text { n jumlah } \\
\text { utuhan tia } \\
n \text { ini mer } \\
\text { lan rendal } \\
\text { netode EC } \\
\text { sama an }\end{array}$ & $\begin{array}{l}2016) \\
1 \quad 8 \text { diket } \\
\text { embelian b } \\
\text { sing meto } \\
\text { u yang dip } \\
\text { engeluaran } \\
\text { beda. Biay } \\
\text { letode pers } \\
\text { n agroindu } \\
\text { agroindus } \\
\text { mungkin d } \\
\text { ak menent } \\
\text { tentunya j } \\
\text { gga rendal } \\
\text { n pengelu } \\
\text { an dilakul } \\
\text { ahan baku } \\
\text { minggu. } \\
\text { gakibatkan } \\
\text { nya biaya } 1 \\
\text { Q, biaya y } \\
\text { ara biaya }\end{array}$ & $\begin{array}{l}\text { hui bah- } \\
\text { han baku } \\
\text { e dikare- } \\
\text { esan sama } \\
\text { biaya pe- } \\
\text { a tertinggi } \\
\text { diaan ba- } \\
\text { tri adalah } \\
\text { ti melaku- } \\
\text { ngan jum- } \\
\text { Kondisi } \\
\text { mlah per- } \\
\text { nya biaya } \\
\text { ran biaya } \\
\text { an setiap } \\
\text { jang dipe- } \\
\text { emesanan } \\
\text { tingginya } \\
\text { esan. Ber- } \\
\text { ang dikel- } \\
\text { pesan dan }\end{array}$ & $\begin{array}{l}\text { metod } \\
\text { perbec } \\
(2015) \\
\text { besarn } \\
\text { dikelu } \\
\text { bedaar } \\
\text { haan } \\
\text { biaya } \\
\text { pesan. } \\
\text { dustri } \\
\text { EOQ } \\
\text { ih ting } \\
\text { mpulk } \\
\text { memil } \\
\text { da-bec } \\
\text { baku } \\
\text { hemat } \\
\text { teknik } \\
\text { yak } 0, \\
\text { pu me } \\
\text { dikare } \\
\text { Baku Me }\end{array}$ & $\begin{array}{l}\text { Berdasal } \\
\text { e, peneli } \\
\text { laan den } \\
\text {. Persan } \\
\text { ya biaya } \\
\text { arkan ole } \\
\text { nya adal } \\
\text { lan LFL } \\
\text { simpan l } \\
\text { Sedangl } \\
\text { Kripik } \mathrm{E} \\
\text { dan LFL } \\
\text { gi diban } \\
\text { Dari ke } \\
\text { an bahn } \\
\text { iki tingk } \\
\text { la. Berd } \\
\text { ketiga } n \\
\text { an biaya } \\
\text { EOQ ya } \\
64 \% \text {. Se } \\
\text { lakukan } \\
\text { nakan to } \\
\text { nggunak }\end{array}$ & $\begin{array}{l}\text { an perban } \\
\text { an ini mem } \\
\text { in penelitia } \\
\text { lan diantar } \\
\text { simpan dar } \\
\text { metode E } \\
\text { perhitung } \\
\text { abrik Decic } \\
\text { ih rendah } \\
\text { in menurut } \\
\text { lah Sanur, } \\
\text { enghasilka } \\
\text { ngkan biay } \\
\text { la peneliti } \\
\text { masing-n } \\
\text { it daya si } \\
\text { arkan tota } \\
\text { tode diata } \\
\text { oersediaan } \\
\text { ni sebesar I } \\
\text { angkan tekı } \\
\text { enghemata } \\
\text { l biaya pe } \\
\text { l Teknik E }\end{array}$ & $\begin{array}{l}\text { dingan } b \\
\text { iliki pers } \\
\text { n Muzay } \\
\text { a kedual } \\
\text { biaya } \\
\text { oQ berir } \\
\text { an meto } \\
\text { acao me } \\
\text { dibandin } \\
\text { peneliti } \\
\text { perhitun } \\
\text { n biaya s } \\
\text { a pesan. } \\
\text { an ini } \\
\text { lasing b } \\
\text { npan ya } \\
\text { persedi } \\
\text { s, diket: } \\
\text { bila me } \\
\text { R. } 486.3 \\
\text { lik LFL } \\
\text { a biaya } \\
\text { tsediaan } \\
\text { DQ }\end{array}$ & $\begin{array}{l}\text { laya antar } \\
\text { amaan dan } \\
\text { yanah dkk } \\
\text { ya adalah } \\
\text { esan yang } \\
\text { ngan. Per- } \\
\text { le perusa- } \\
\text { ghasilkan } \\
\text { kan biaya } \\
\text { n Agroin- } \\
\text { gan teknik } \\
\text { mpan leb- } \\
\text { apat disi- } \\
\text { han baku } \\
\text { ng berbe- } \\
\text { tan bahan } \\
\text { hui peng- } \\
\text { ggunakan } \\
88 \text {, seban- } \\
\text { dak mam- } \\
\text { ersediaan, } \\
\text { LFL lebih }\end{array}$ \\
\hline Bahan Ba & & $\begin{array}{l}\text { iaya Pesan } \\
\text { (Rp) }\end{array}$ & Biay & $\begin{array}{l}\text { Simpan } \\
\text { (Rp) }\end{array}$ & $\begin{array}{r}\text { Biaya } \\
\text { Bah: } \\
\end{array}$ & $\begin{array}{l}\text { embelian } \\
\text { Baku } \\
\text { p) }\end{array}$ & $\begin{array}{r}\text { Total B } \\
\text { sedia: }\end{array}$ & $\begin{array}{l}\text { aya Per- } \\
\text { n (Rp) }\end{array}$ \\
\hline Salak & & 140.0 & & $183.378,3$ & & 5.310 .000 & 35. & $33.378,3$ \\
\hline Nangka & & 110.0 & & 116.032 & & 4.608 .000 & & .834 .032 \\
\hline Pisang & & 40.0 & & 52.100 & & 3.179 .000 & & .271 .100 \\
\hline Nanas & & 20.0 & & 5.110 & & 1.477 .000 & & .502 .110 \\
\hline
\end{tabular}

Sumber : Data Primer Diolah (2016). 
Tabel 8. Perbandingan Biaya Persediaan Bahan Baku

\begin{tabular}{lrrrrr}
\hline Metode & $\begin{array}{c}\text { Frekuensi } \\
\text { (kali) }\end{array}$ & $\begin{array}{c}\text { Biaya Pesan } \\
\text { (Rp) }\end{array}$ & $\begin{array}{c}\text { Biaya Sim- } \\
\text { pan (Rp) }\end{array}$ & $\begin{array}{c}\text { Pembelian } \\
\text { Bahan Baku } \\
\text { (Rp) }\end{array}$ & $\begin{array}{c}\text { Total Perse- } \\
\text { diaan (Rp) }\end{array}$ \\
\hline Agroindustri & 96 & 960.000 & 193.008 & 74.574 .000 & 75.727 .008 \\
EOQ & 31 & 310.000 & 356.620 & 74.574 .000 & 75.240 .620 \\
LFL & 47 & 470.000 & 1.179 .566 & 74.574 .000 & 76.223 .566 \\
\hline
\end{tabular}

Sumber : Data Primer Diolah (2016).

tinggi dibandingkan perhitungan persediaan

bahan baku yang diterapkan Agroindustri

Kripik Buah Sanur.

Dari perbandingan total biaya persediaan bahan baku Agroindustri Kripik Buah Sanur pada tahun 2015, metode MRP teknik EOQ memiliki persediaan bahan baku paling ekonomis.

\section{Pemesanan Ulang Bahan Baku}

Pemesanan ulang bahan baku yang diterapkan Agroindustri Kripik Buah Sanur tidak diketahui nilai safety stock, nilai persediaan minimum dan jumlah pemesanan bahan baku secara pasti. Perhitungan total biaya persediaan atau Total Inventory Cost (TIC) pada Agroindustri Kripik Buah Sanur masih menggunakan perhitungan yang sederhana. Berikut ini perhitungan Total Inventory Cost Agroindustri Kripik Buah Sanur

$\mathrm{TIC}_{\text {perusahaan }}=$ (rata-rata penggunaan $\times$ biaya penyimpanan $)+($ biaya pemesanan $\times$ frekuensi pembelian).

Pada perhitungan pemesanan ulang bahan baku menggunakan metode Re-Order Point diperoleh nilai safety stock, nilai persediaan minimum dan jumlah pemesanan bahan baku secara pasti. Berikut hasil perhitungan

dan perbandingan metode pemesanan ulang bahan baku yang diterapkan agroindustri dan metode Re-Order Point.

Berdasarkan tabel 9, diketahui nilai yang diperoleh bila menggunakan metode ROP lebih efisien dan lebih pasti daripada metode pemesanan ulang tradisional yang diterapkan Agroindustri Kripik Buah Sanur. Hasil penelitian ini sama dengan penelitian Artawan (2015), yang menunjukkan bahwa pemesanan ulang bahan baku mengalami penurunan biaya apabila menggunakan metode ROP. ROP juga mampu menentukan kapan waktu yang baik untuk melakukan pemesanan ulang bahan baku dengan diketahuinya safety stock.

\section{KESIMPULAN}

Berdasarkan hasil pembahasan dapat disimpulkan bahwa: Total biaya persediaan bahan baku yang dikeluarkan Agroindustri Kripik Buah Sanur, teknik LFL dan teknik EOQ berturut-turut adalah Rp. 75.727.008, Rp. 76.223.566, Rp. 75.240.620, dari biaya persediaan yang dikeluarkan, metode EOQ mampu meminimalkan biaya persediaan bahan baku; Metode pemesanan ulang bahan baku menggunakan metode Re-Order Point dapat digunakan untuk menentukan nilai safety stock,

Tabel 9. Perbandingan Metode Pemesanan Ulang Bahan Baku

\begin{tabular}{lrrrrr}
\hline \multicolumn{1}{c}{ Produk } & Metode & $\begin{array}{c}\text { Pemesanan } \\
\text { Bahan baku } \\
(\mathbf{K g})\end{array}$ & $\begin{array}{l}\text { Safety Stock } \\
\mathbf{( K g )}\end{array}$ & $\begin{array}{c}\text { Titik Peme- } \\
\text { sanan Ulang } \\
\text { Bahan Baku } \\
(\text { Kg) }\end{array}$ & TIC (Rp) \\
\hline Salak & Agroindustri & Tidak tentu & Tidak tentu & Tidak tentu & 623.510 \\
& ROP & 885,8 & 342,9 & 770,9 & 265744 \\
Nangka & Agroindustri & Tidak tentu & Tidak tentu & Tidak tentu & 396.356 \\
& ROP & 1.123 & 184,8 & 1.008 & 196.870 \\
Pisang & Agroindustri & Tidak tentu & Tidak tentu & Tidak tentu & 265.320 \\
& ROP & 398,7 & 89,9 & 248,8 & 79.737 \\
Nanas & Agroindustri & Tidak tentu & Tidak tentu & Tidak tentu & 64.770 \\
& ROP & 347 & 23 & 191,8 & 24.306 \\
\hline Sumber: Data Primer Diolah (2016). & & & &
\end{tabular}


jumlah pemesanan bahan baku, titik pemesanan ulang bahan baku. Metode ROP juga mampu mengefisiensikan pemesanan ulang bahan baku.

\section{DAFTAR PUSTAKA}

Artawan, I Wayan. 2015. Analisis Ketepatan Waktu dalam Pemesanan Bahan Baku dengan Metode Re-order Point (ROP) pada Rumah Makan Janggar Ulam di Kecamatan Ubud. Jurnal. Vol : 5 No : 1 .. Departemen Pertanian. 2005. Revitalisasi Pertanian Melalui Agro Industri

Perdesaan. Direktorat Jenderal Bina Pengolahan dan Pemasaran Hasil Pertanian monograph 2005 Masalah-Masalah yang dihadapi dalam Pembangunan Agro industri di Indonesia. Pasar Minggu,Jakarta.

Haming,Murdifin dan Nurnajamuddin, Mahfud. 2012. Manajemen Produksi Modern Operasi Manufaktur dan Jasa. Jakarta : PT. Bumi Aksara.

Haming, Murdifin dan Nurnajamuddin, Mahfud. 2012. Manajemen Produksi Modern Operasi Manufaktur dan Jasa. Jakarta : PT. Bumi Aksara.

Herdjanto, Eddy. 2007. Manajemen operasi. Jakarta : PT. Gramedia.

Muzayyanah., Suamba, I Ketut dan Dewi, Ratna Komala. 2015. Analisis Pengendalian Persediaan Bahan Baku Biji Kakao pada Pabrik Delicacao Bali di Kabupaten Tabanan. E-Jurnal Agribisnis dan Agrowisata. Vol.4, No.4.

Soekartawi. 2005. Agroindustri dalam Perspektif Sosial Ekonomi. Jakarta : PT Raja Grafindo Persada. 